\title{
EM BUSCA DOS SIGNIFICANTES QUE AMARRAM AS ANGÚSTIAS DE RODRIGO S. M. E MACABÉA EM A HORA DA ESTRELA, DE CLARICE LISPECTOR
}

\author{
IN SEARCH OF THE SIGNIFIERS THAT TIE THE ANGUISHES OF RODRIGO S. M. \\ AND MACABÉA IN THE HOUR OF THE STAR, BY CLARICE LISPECTOR
}

\section{Gustavo Oliveira dos Santos ${ }^{1}$}

RESUMO: Orientando-se, principalmente, por uma perspectiva psicanalítica, este artigo objetiva identificar os significantes que amarram as angústias vivenciadas pelo narrador Rodrigo S. M. e pela protagonista Macabéa na novela A hora da estrela, de Clarice Lispector. Sua metodologia é o levantamento bibliográfico e seu propósito é contribuir com as pesquisas preocupadas com as relações entre a angústia e a literatura. Constam como resultados dois e três significantes vinculados a S. M. e Macabéa, respectivamente, a saber: no caso do narrador, sua meta de escrever a história da personagem e, como consequência da efetuação dessa operação, seu medo da morte; no caso da protagonista, os traumas advindos da criação pela tia, a opressão classista por parte de seu namorado Olímpico e a rejeição de caráter sexista e sulista por parte do mesmo companheiro.

Palavras-chave: angústia. Impulso. Psicanálise. Significantes. trauma.

ABSTRACT: Mainly guided by a psychoanalytic perspective, this article aims to identify the signifiers that bind the anguish experienced by the narrator Rodrigo S. M. and by the protagonist Macabéa in Clarice Lispector's novel The hour of the star. Its methodology is the bibliographic survey and its purpose is to contribute to researches concerned with the relationship between anguish and literature. There are two and three signifiers linked to $S$. M. and Macabéa, respectively, as results, namely: in the case of the narrator, his goal of writing the character's story and, as a consequence of carrying out this operation, his fear of death; in the case of the protagonist, the traumas arising from the upbringing by her aunt, the class oppression by her boyfriend Olímpico and the rejection with a sexist and southern character by the same partner.

Keywords: Anguish. Impulse. Psychoanalysis. Significant. Trauma.

\footnotetext{
${ }^{\text {I }}$ Estudante de Licenciatura em Língua Portuguesa e Literaturas de Língua Portuguesa, da Universidade Federal do Espírito Santo (UFES).
} 


\section{INTRODUÇÃO}

Em sua dissertação de mestrado sobre A hora da estrela, Bianca Cardoso Batista considera, dentre os tipos de angústia que identifica na narrativa, "a angústia que emerge do narrador através dos pensamentos e reflexões deste em relação à Macabéa e à vida, de modo geral" (2018: p. 66) e "a angústia inconsciente de Macabéa, que se queixa de uma dor interior - remediada com aspirinas” (2018: p. 66). Baseando-se nisso, procurou-se, neste artigo, desenvolver esses dois tipos de angústia com autores que, classicamente, são utilizados para discutir filosoficamente esse afeto, como os filósofos Jean-Paul Sartre e Martin Heidegger, autores, aliás, a que a própria Batista recorre (2018: p. 97, 99), mas por uma perspectiva em que as literaturas psicanalíticas de Sigmund Freud e Jacques Lacan ocupem o lugar de maior destaque neste artigo Soma-se a esses, autores menos conhecidos, mas inspirados por seus trabalhos, dentre os quais se destaca a professora universitária brasileira Sonia Leite.

Diante do exposto acima, é importante explicitar que a angústia, seguindo Lacan, é compreendida como um afeto (2005: p. 23) neste trabalho. Isso porque, conforme diz esse psicanalista, não é possível, como todo afeto, recalcar a angústia, mas apenas os significantes $^{2}$ que a amarram. É à procura dos significantes a amarrarem as angústias do narrador-escritor Rodrigo S. M. e de sua criatura, a protagonista Macabéa, que este texto está. No caso de S. M., seus significantes são os produzidos pela recusa dos prazeres sexuais para se rebaixar ao que ele afirma ser o nível de sua pobre personagem? E, no caso de Macabéa, estarão ligados ao fato de ela ter crescido e vivido sob opressões e rejeições diversas: ora a advinda de sua tia carrasca, responsável por sua criação, ora pelo namorado machista Olímpico de Jesus Moreira Chaves, ora por sua condição de pobreza que a faz até ser preterida por esse namorado, a correr, posteriormente, para os braços de sua colega de trabalho, a estenógrafa Glória? São a essas e outras questões que o artigo se propõe a responder, com o intento de contribuir às pesquisas sobre as relações entre angústia e literatura. Afinal, aproveitar a novela de Clarice Lispector para discorrer sobre esse afeto é falar de algo que constitui o ser humano como tal: sujeito desejante, atravessado por uma sensação de falta, mas que luta contra suas tensões internas em prol do desfrute de fragmentos de prazer, enquanto a morte não lhe é uma realidade para nivelar essas mesmas tensões.

\section{A angústia vivenciada pelo narrador-escritor S. M.}

Se, em O ser e o nada - Ensaio de ontologia fenomenológica, Sartre caracteriza a realidade humana como sendo, por natureza, "consciência infeliz, sem qualquer possibilidade de superar o estado de infelicidade" (Sartre, 201I: p. I4I), e "falta" (Sartre, 2011: p. 138), em A

\footnotetext{
${ }^{2}$ A noção de significante trabalhada aqui advém da linguística estruturalista, onde, via Ferdinand de Saussure no Curso de linguística geral, aprende-se que "O signo linguístico une não uma coisa e uma palavra, mas um conceito e uma imagem acústica” (2006: p. 80). Ou seja, une-se o conceito (parágrafos adiante no mesmo livro saussuriano, chamado de significado) à impressão psíquica desse som (também chamado de significante) (2006: p. 8o, 81) e têm-se a significação, "subproduto de um jogo potencialmente interminável de significantes" (Eagleton, 2006: p. 192). Trazendo essa explicação para o plano da perspectiva psicanalítica, compreende-se que tudo que é "capaz de atribuir significação" é um significante. Considerando os objetivos deste artigo, dispõese a identificar os significantes que produzem significação de angústia nas vivências de Rodrigo S. M. e Macabéa.
} 
hora da estrela, Lispector apresenta um exemplar bastante representativo de tal realidade: o narrador-escritor da história. Identificado como Rodrigo S. M., não se trata de uma personagem feliz ("Felicidade? Nunca vi palavra mais doida, inventada pelas nordestinas que andam por aí aos montes." (Lispector, 2020: p. Io)) ou realizada ("Meu coração se esvaziou de todo desejo e reduz-se ao próprio último ou primeiro pulsar." (Lispector, 2020: p. 9-10)), nem tampouco orgulhosa de seus feitos ("Também eu, de fracasso em fracasso, me reduzi a mim mas pelos menos quero encontrar o mundo e seu Deus." (Lispector, 2020: p. 16)). É, na verdade, um homem que, embora alegue precisar "não fazer a barba e adquirir olheiras escuras por dormir pouco" (Lispector, 2020: p. 17), por exemplo, para se "pôr ao nível da nordestina" (Lispector, 2020: p. 17), frequentemente se depara com um vazio em sua vida, estando ou não em situações em que precisa escrever a história de uma personagem tão marcada por essa mesma condição existencial, como é o caso da alagoana Macabéa.

S. M. é um homem que sente que vive para nada (Lispector, 2020: p. 29), mas reconhece seu vazio como algo que "tem o valor e a semelhança do pleno" (Lispector, 2020: p. 12). Contudo, ele precisa preenchê-lo porque, como ser humano, é um ser que deseja. Como escreve Sartre:

\footnotetext{
Por si mesmo, o desejo tende a perpetuar-se; o homem se apega encarniçadamente a seus desejos. O que o desejo almeja é ser um vazio preenchido que forma sua repleção assim como um molde forma o bronze vertido dentro dele. (Sartre, 2orr: p. 154)
}

Um dos desejos de S. M. é "falar dessa nordestina" (Lispector, 2020: p. 15) para não se sufocar, para alimentar, pois, o seu desejo. Ele, porém, não se satisfaz absolutamente enquanto escreve a narrativa. Como escritor que se diz sem classe social (Lispector, 2020: $\mathrm{p}$. I6), ele demonstra detestar o universo marcado pela pobreza de Macabéa, chamando até a condição social da própria personagem de "feia e promíscua" (Lispector, 2020: p. 19). Também, não se furta a denunciar que a própria história é "simples demais" (Lispector, 2020: p. I6), sem nenhuma técnica ou estilo (Lispector, 2020: p. 32). Sintetizando, ao rumar em direção ao que considerava ser uma possibilidade de existência de maior satisfação pessoal, S. M. permanece com um vazio. Sua liberdade de escolha não o liberta de sua angústia porque a sua angústia é materializada pelo exercício de sua liberdade de escolha. Consoante ao que explica Sartre:

[...] angústia é reconhecimento de uma possibilidade como minha possibilidade, ou seja, constitui-se quando a consciência se vê cortada de sua essência pelo nada ou separada do futuro por sua própria liberdade. [grifo do autor] (20II: p. 8o)

Nota-se, da leitura dessa afirmação, que o vazio de S. M, é um nada, apesar de ser necessário observar que não se trata aqui de um "vazio indiferenciado" (Sartre, 20Ir: p. 60).

Embora o nada seja "a negação da totalidade do ente" (Heidegger apud. Souza, 2019: p. 150), ele não é "o que não há" (Heidegger apud. Souza, 2org: p. I49). Haja vista que a negação é "uma operação específica do intelecto" (Heidegger apud. Souza, 2019: p. 150) e o nada é uma negação, o nada é algo "inquietante a alguém” (Heidegger apud. Souza, 2019: p. 154), é algo manifestado por sua angústia (Heidegger apud. Souza, 2019: p. 154). 
Esse mesmo nada poderia ser entendido como, simplesmente, derivado do fato de ser marcado "primariamente pela falta" (Leite, 2oII: p. 76), tal como todo ser humano é. Não obstante, há o agravante, no caso de S. M., de que ele se encontra em evasão da própria existência, haja vista que, de acordo com a pós-doutora em sucidologia Karina Okajima Fukumitsu, esse estado de autodesalojamento se caracteriza justamente, junto com o estresse, a sobrecarga e o sofrimento existencial, pela falta de crença em si mesmo (2018: p. 104).

Essa perda de autoconfiança é contemplada, por exemplo, no momento em que o escritor se dispõe a elaborar o destino de Macabéa, mas ele afirma que não se sente "com o poder de livremente inventar" (Lispector, 2020: p. I8). Como explicação para isso, têm-se que Sartre diz que, "Na angústia, a liberdade se angustia diante de si porque nada a solicita ou obstrui jamais" [grifo do autor] (2011: p. 79). No caso do narrador-escritor, esse nada, porque corta a palavra e, assim, impossibilita-lhe de dar sentido ao que sente (Bondía, 2002: p. 2I) enquanto pensa na história, atua como um obstrutor desse ente chamado S. M. (Heidegger apud. Souza, 2019: p. 155). Paradoxalmente, porém, como única pessoa que concebeu o universo narrativo de Macabéa em seu inconsciente, somente ele conhece as palavras que mediam o processo de realização desse outro (Lacan, 1986: p. 6I), esse não-eu em relação ao sujeito S. M., que é Macabéa, mas que se define, em termos gerais, como uma “inconsciência constituída como tal” (Lacan, 2005: p. 32).

Como S. M. mesmo expressa ao se referir à sua protagonista, é paixão sua "ser o outro. No caso a outra." (Lispector, 2020: p. 37), porque, entrelaçando a sua história de vida à de sua personagem, ele espera saciar o seu desejo e até mesmo o que ele acredita ser os desejos de Macabéa. Essa situação acha abrigo na afirmação de Lacan de que "O Outro concerne a meu desejo na medida do que lhe falta e de que ele não sabe" (2005: p. 32): apesar de S. M. desprezar a realidade social de Macabéa, ele vivencia, como decorrência do processo de angústia, uma relação essencial com o Outro (Lacan, 2005: p. 14). Por isso, embora de forma paternalista, não é equivocado expressar que ele é sincero quando expressa, por exemplo, que a ama em:

E assim se passava o tempo para a moça esta. Assoava o nariz na barra da combinação. Não tinha aquela coisa delicada que se chama encanto. Só eu a vejo encantadora. Só eu, seu autor, a amo. Sofro por ela. E só eu é que posso dizer assim: "que é que você me pede chorando que não lhe dê cantando"? [...] [grifo meu] (Lispector, 2020: p. 24).

Todavia, alimentando a própria angústia por meio dessa relação essencial que passa a manter com Macabéa, S. M. se torna incapaz de instaurar uma distância entre os seus desejos e os desejos de sua personagem, o que impede-lhe de ser uma pessoa menos insatisfeita com a própria vida (Leite, 2011: p. 77). Mais detalhadamente, o que lhe ocorre é ser incapaz de se apropriar pessoalmente desse determinismo inconsciente, chamado Macabéa, por meio de uma mediação simbólica que lhe permita assimilar "a dimensão trágica" (Leite, 20II: p. 77) da vida de sua personagem, sem que ele mesmo se machuque. Como resultado de estar envolvido nessa "relação de alteridade fundamental" (Lacan, 1985: p. 297), em que o outro (ou a outra) é sua imagem, S. M. não consegue encontrar "a medida para a sua felicidade" (Leite, 2011: p. 77). 
Uma passagem que comprova a sua incapacidade de separar os próprios afetos dos de Macabéa é a seguinte, a saber:

[...] Para desenhar a moça tenho que me domar e para poder captar sua alma tenho que me alimentar frugalmente de frutas e beber vinho branco gelado pois faz calor neste cubículo onde me tranquei e de onde tenho a veleidade de querer ver o mundo. Também tive que me abster de sexo e de futebol. Sem falar que não entro em contacto com ninguém. Voltarei algum dia à minha vida anterior? Duvido muito. Vejo agora que esqueci de dizer que por enquanto nada leio para não contaminar com luxos a simplicidade de minha linguagem. [...] [grifo meu] (Lispector, 2020: p. 20)

Como se lê, para sentir-se como uma pessoa que vive de forma tão mesquinha quanto a própria Macabéa, ele se abstém de diversos prazeres, a saber: alimentação em excesso, prática esportiva, socialização e prazer sexual. Porém, dos deleites que recusa, o que é mais pertinente de se destacar quando se discute a questão da angústia pela perspectiva psicanalítica é, como é de se imaginar, o sexual, uma vez que revela que a interferência desse afeto em S. M. como impedimento a um desenvolvimento mais fluídico de seu texto é derivada dessa sublimação de sua libido. Isto é, a força da angústia advinda de não poder se satisfazer sexualmente a fim de sentir-se como a personagem imaginada foi desviada para a tarefa de construir uma história que lhe soe aceitável (Mendes, 201r: p. 55). Em outras palavras, escrever sua história não é uma tarefa qualquer que S. M. deseja realizar, mas a meta a qual os seus instintos libidinais se lançam, envolvidos pela tendência de afastaremse do que é sexual (Freud, 2010: p. 28).

Essa meta é o primeiro significante que amarra a sua angústia. Afinal, se há preocupação por parte do autor com a possibilidade de não escrever esse texto, isso quer dizer que ele vislumbra um perigo, o que é característico do afeto angustiante. Como já foi mencionado, o perigo é o de sufocar-se como consequência do não-preenchimento de seu desejo. Psicanaliticamente, o fato de conhecer esse perigo classificaria esse tipo de angústia como realista, porque sintetiza Freud que "Perigo real é um perigo que conhecemos, e angústia realista é a angústia ante tal perigo conhecido" (2014: p. 85). O outro tipo de angústia, chamado de angústia neurótica, "é a angústia ante um perigo que não conhecemos" (Freud, 2014: p. 85). Porém, como a angústia de S. M. se dá em níveis exagerados - ao ponto de, em momentos distintos da novela (conforme já mostrado), sempre se perguntar se o seu texto está satisfatório -, percebe-se a existência de um elemento neurótico, que vem à luz, principalmente, nesses excessos de angústia. Como se percebe no texto, o perigo que S. M. não conhece é o medo da morte (o segundo significante). Mais precisamente, seus instintos de morte se afloram mais enquanto descreve detalhadamente a morte de Macabéa como resultado de seu atropelamento por um carro amarelo (Lispector, 2020: p. 8I). Ademais, atingem o clímax quando, ao término do livro, ele revela que tomou consciência de sua própria finitude, a saber: "Meu Deus, só agora me lembrei que a gente morre. Mas - mas eu também?!” (Lispector, 2020: p. 78).

Assim, os níveis esperados de angústia (isto é, que não prejudicariam a escrita do literato) diante da possibilidade de não conseguir terminar a história se revelam como decorrência da existência de um perigo real, isto é, sentir-se ainda mais impotente como escritor como desdobramento dessa não-finalização de seu trabalho. Mas os excessos se materializam em consequência de "um perigo instintual não reconhecido" (Freud, 2014: p. 
85) como tal, mas que lhe causa perturbação psicológica constante, que é o medo da morte, derivado dos instintos de morte.

Ao falar de instinto, é importante mencionar que a psicanálise freudiana não o entende como uma força que provoca a alteração de um estado presente de um indivíduo ou mesmo a sua renovação interior, mas como "um impulso, presente em todo organismo vivo, tendente à restauração de um estado anterior" [grifo do autor] (Freud, 20ı: p. 147-I48). Simanke até o define como um "conservadorismo retrógrado" (2014: p. 76), haja vista que não apenas o indivíduo não evolui, como tende não a responder aos seus instintos de vida, mas aos instintos de morte (Simanke, 2014: p. 76); ou, nas palavras do próprio Freud, "o processo vital do indivíduo conduz, por razões internas, ao nivelamento das tensões químicas, ou seja, à morte" (2010: p. 165).

Em síntese, o "perigo instintual não reconhecido" (Freud; 2014; p. 85), derivado do elemento neurótico da angústia de S. M., se encontra ligado ao "perigo real conhecido" (Freud, 20I4: p. 85), derivado do elemento realista. Em outras palavras, a angústia de S. M. é um dos casos "em que características da angústia realista e da angústia neurótica aparecem mescladas" (Freud, 2014: p. 85). Com isso, nota-se que a morte não é um tema isolado na vida de S. M., nem tampouco é um tema de que pretende se afastar mentalmente, até porque narrador-escritor não compreende o seu encontro com esse tema como algo puramente negativo. Embora explicite que falar da morte, pensar na morte ou mesmo morrer não o faz preencher o vazio que o acompanha desde o início da novela - "O melhor negócio é ainda o seguinte: não morrer, pois morrer é insuficiente, não me completa, eu que tanto preciso." (Lispector, 2020: p. 87) -, a morte lhe é, ainda assim, um momento de glória para o ser humano, ao mesmo tempo em que ele paradoxalmente a teme. Em consonância com a sua valorização da morte, não são raros os trechos em que esse tema permeia a narrativa. Para exemplificar, citam-se os trechos a seguir:

[...] bem sei que cada dia é um dia roubado da morte. [...] [grifo meu] (Lispector, 2020: p. 14)

[...] na hora da morte a pessoa se torna brilhante estrela de cinema, é o instante de glória de cada um e é quando como no canto coral se ouvem agudos sibilantes. [grifo meu] (Lispector, 2020: p. 25)

[...] Terei castigo de morte por falar de uma vida que contém como todas um segredo inviolável? [...] [grifo meu] (Lispector, 2020: p. 35)

[...] Se ainda escrevo é porque nada mais tenho a fazer no mundo enquanto espero a morte. [...] [grifo meu] (Lispector, 2020: p. 63)

[...] A morte que é nesta história o meu personagem predileto. [...] [grifo meu] (Lispector, 2020: p. 76)

[...] A morte é um encontro consigo. [...] [grifo meu] (Lispector, 2020: p. 78)

Como explicação para o seu temor, têm-se que a literatura psicanalítica não toma como uma atitude comum perante a vida a aceitação tácita da morte em nossa civilização. Como escreve Freud, "no fundo, ninguém acredita na sua própria morte ou, o que é a mesma coisa, no inconsciente, cada qual está convencido da sua imortalidade” (2009: p. 2I). Já a justificativa para o paradoxo se encontra no fato de que, por mais que não expresse querer 
morrer por suicídio, os resultados que Rodrigo S. M. colheu de sua vida não lhe parecem satisfatórios, pois não é vivida no sentido pleno do termo.

Se, como aponta Lacan, "o amor é uma forma de suicídio” (1986: p. i85), S. M. vivencia essa morte em vida em razão do amor que devota à Macabéa. Não é adequado, pois, entender o seu dito em "Macabéa me matou." (Lispector, 2020: p. 78) ou em "[...] Eu estive na terra dos mortos... [...]” (Lispector, 2020: p. 77) como pura metáfora. Como explica Fukumitsu, o definhar existencial de um ser humano não se dá de imediato, mas gradualmente, por meio do que a pesquisadora chama de "processo de morrência", o qual "exibe uma complexidade de comportamentos autodestrutivos que, de maneira gradativa, provocam o esvaziamento de quem somos" (2016: p. 166) e, assim, encaixa-se com o contexto de vida de quase total anedonia (incapacidade de sentir prazer) vivenciado pelo narradorescritor.

Concluindo e sintetizando, têm-se dois significantes a amarrar a angústia de S. M.. O primeiro é o impulso libidinal, decorrente da falta de prazer sexual que o absorve para se "pôr ao nível da nordestina" (Lispector, 2020: p. 17). O segundo é o medo da morte, como consequência do fato de amar Macabéa tão profundamente ao ponto de entrelaçar os seus afetos aos dela (sente-se morto quando ela morre, por exemplo) e, como decorrência de todo amor, morrer em vida.

\section{A angústia vivenciada pela protagonista Macabéa}

A personagem principal da novela A hora da estrela tem uma vida marcada por dramas e sofrimentos. No sertão de Alagoas, nasceu essa menina raquítica - e, portanto, com "os ossos fracos por falta de cálcio" (Lispector, 2020: p. 25) - chamada Macabéa. Com um ano de idade, a garota recebeu esse nome incomum por uma promessa que sua mãe fizera à Nossa Senhora da Boa Morte de que assim lhe batizaria se a pequena Maca (seu apelido) não morresse até o seu primeiro aniversário. Quem, porém, faleceu antes de Macabéa foi a sua própria mãe, que, como o pai, não pôde conviver mais com a filha a partir dos dois anos de idade, uma vez que eles faleceram adoentados. Sobrou à protagonista então viver com uma tia beata e que, mais tarde, mudou-se com a sobrinha para Maceió (Lispector, 2020: p. 24-25).

Contudo, Maca não estava sendo tutelada por nenhum modelo de como educar uma criança. Pelo contrário: essa tia sentia tanto prazer em agredir a sobrinha com cascudos e acabou traumatizando-a tão severamente, que, depois de adulta, "Quando dormia quase que sonhava que a tia lhe batia na cabeça" (Lispector, 2020: p. 30). No entanto, Macabéa, como uma prova de sua personalidade passiva, cresceu acreditando que "o que a tia lhe fizera era educá-la para que ela se tornasse uma moça mais fina" (Lispector, 2020: p. 69). Ou seja, seu ego normalizou a agressão sofrida, mas o seu inconsciente não. $O$ sofrimento que a parente lhe causa é, pois, o primeiro significante que amarra a angústia de Macabéa.

Esta seção se inicia com a contação de todas essas tragédias porque, como foi mostrado na anterior, dentre os motivos que podem desencadear a evasão da própria existência, está o sofrimento existencial (Fukumitsu, 2018: p. 104). Disso, depreende-se que não é pertinente desvincular o sofrimento que permeia a vida de Macabéa desde sua infância das crises de angústia vivenciadas na fase adulta.

Um trecho em que essas crises são explicitadas na narrativa é o disposto abaixo, a saber: 
[...] Quando voltou para a sala de trabalho Glória riu-se dela:

- Você endoidou, criatura? Pintar-se como uma endemoniada? Você até parece mulher de soldado.

- Sou moça virgem! Não sou mulher de soldado e marinheiro.

- Me desculpe eu perguntar: ser feia dói?

- Nunca pensei nisso, acho que dói um pouquinho. Mas eu lhe pergunto se você que é feia sente dor.

- Eu não sou feia!!!, gritou Glória.

Depois tudo passou e Macabéa continuou a gostar de não pensar em nada. Vazia, vazia. Como eu disse, ela não tinha anjo da guarda. Mas se arranjava como podia. Quanto ao mais, ela era quase impessoal. Glória perguntou-lhe:

- Por que é que você me pede tanta aspirina? Não estou reclamando, embora isso custe dinheiro.

- É para eu não me doer.

- Como é que é? Hein? Você se dói?

- Eu me doo o tempo todo.

- Aonde?

- Dentro, não sei explicar. (Lispector, 2020: p. 56)

Lê-se acima que Macabéa se sente vazia, mas não é acometida por um vazio ausente. Ele se encontra "dentro" (Lispector, 2020: p. 56), como ela mesma explica vagamente. Afinal, o vazio vivenciado pelo sujeito angustiado não é, como foi visto na seção anterior, um nada no sentido do "que não há" (Heidegger apud. Souza, 2019: p. I49), mas, como uma negação, isto é, como "uma operação especifica do intelecto" (Heidegger apud. Souza; 2019; p. I5o), o nada existe e é algo "inquietante à alguém”" (Heidegger apud. Souza, 2019: p. 154).

A angústia, porém, não se esgota no plano da inquietação. É importante considerar que "a palavra "angústia" relaciona-se, especificamente, à ideia de estreitamento, limitação, redução" (Leite, 2oIr: p. 74). No entanto, Macabéa não sente essa estreiteza apenas como uma consequência advinda do meio externo. Se, para a psicanálise, uma pessoa angustiada tem como principal ferramenta para iluminar a sua vida e recobrir a sua sensação de desamparo a palavra (Leite, 20II: p. 56), poder-se-ia partir do pressuposto de que, ao procurar uma saída medicamentosa, a personagem estaria procurando dar voz a si, mas não é o que acontece. Ao procurar uma saída para o seu sofrimento pela via medicamentosa (mais precisamente, pelo consumo de aspirina), ela encontra algo que mais a silencia do que trata de seu problema (Leite, 20II: p. 31). Mais especificamente, embora a personagem se alivie psicologicamente e silencie a sua inquietação, ela se exclui, após ingerir a aspirina, da responsabilidade sobre o seu sintoma e, assim, perde as possibilidades de inscrição de si e do seu desejo ao confiar acriticamente no discurso médico hegemônico (Leite, 20II: p. 37-38).

Não obstante, é importante ressaltar que Macabéa, ao longo da história, até procura a "reinscrição do desejo como expressão do movimento da [sua] vida" (Leite, 20II: p. 7I) a partir do instante em que inicia um namoro com o metalúrgico paraibano Olímpico de Jesus Moreira Chaves. Mas trata-se de uma relação breve e sem vestígios de envolvimento emocional significativo. Além disso, ela namora e verdadeiramente o amava, como se lê, por exemplo, em " "[...] ela já o amava tanto que não sabia mais como se livrar dele, estava em desespero de amor" (Lispector, 2020: p. 39). Mas esse sentimento não era recíproco, haja vista que ele entendia que o seu lugar como mulher na sociedade deveria conformar-se às suas visões machistas, como se nota abaixo:

Na Rádio Relógio disseram uma palavra que achei meio esquisita: mimetismo. Olímpico olhou-a desconfiado: 
- Isso é lá coisa para moça virgem falar? E para que serve saber demais? O Mangue está cheio de raparigas que fizeram perguntas demais.

- Mangue é um bairro?

- É lugar ruim, só pra homem ir. Você não vai entender mas eu vou lhe dizer uma coisa: ainda se encontra mulher barata. Você me custou pouco, um cafezinho. Não vou gastar mais nada com você, está bem?” (Lispector, 2020: p. 49-5o)

Percebe-se, acima, a tentativa de Olímpico de controlar duas de suas liberdades: a de ir e vir (ao dizer para ela que o mangue não é um local em que uma mulher pode entrar) e a de expressão (ao reagir ao fato de ela ter aprendido uma palavra desconhecida para ambos, mas que ele já pré-concebia ser de teor sexual). Nos dois casos, Macabéa ser mulher motiva Olímpico a tratá-la como um ser inferior porque a lei dominante em uma cultura masculinista (como é o caso da brasileira) é tornar o Outro feminino radicalmente dependente do sujeito masculino (Butler, 2003: p. 7). Atuando, pois, como Outro para Olímpico, a protagonista não consegue estabelecer o que já foi chamado de "relação de alteridade fundamental" (Lacan, 1985: p. 297) com o seu companheiro e, assim, encontrar "a medida para a sua felicidade" (Leite, 20II: p. 77). Afinal, ela atua como um Outro feminino aos olhos dele, mas, nessa relação desigual de poder, ele não atua como um Outro masculino aos olhos dela. Durante toda a relação, ela é o Outro-significado e ele, o sujeito-significador (Butler, 2003: p. 29). Portanto, embora ambos compartilhassem a mesma pertença à classe trabalhadora e à região nordeste do país, esses fatos em comum não foram suficientes para que os dois desfrutassem de um relacionamento amoroso saudável para ambas as partes, pois, refletindo a lógica machista da sociedade, Macabéa era oprimida por ele.

Olímpico tinha ainda o desejo de ascender socialmente, pretendia ser deputado (Lispector, 2020: p. 4I). Macabéa pretendia parecer-se com a atriz de cinema estadunidense Marilyn Monroe (Lispector, 2020: p. 58), mas, na narrativa, isso é confessado apenas à Glória e, em nenhum momento, o narrador ou a própria personagem explicita que tem o intento de, factualmente, recorrer a uma produtora de cinema ou a uma agência para ser uma atriz ou uma modelo, respectivamente. Portanto, pode-se dizer que é um desejo mais genérico e que não há evidências de que deslocar-se em direção a uma classe social "superior" seja algo que move a vida da alagoana. Porém, ser deputado é uma ambição de Olímpico. Tanto que o próprio narrador denuncia que, "No futuro, que eu não digo nesta história, não é que ele terminou mesmo deputado?” (Lispector, 2020: p. 4I).

Rodrigo S. M. não explicita ao leitor se, quando tornou-se deputado, ainda namorava Glória, mas é um fato que, quando ele finda o namoro com Macabéa para ficar com essa estenógrafa e colega de trabalho justamente da ex-namorada, não é apenas por ela ser uma mulher atraente: Olímpico entende que namorar Glória é mais condizente com o seu interesse de pertencer às elites políticas. Como o próprio narrador afirma, Glória:

[...] era loura, o que significava um degrau a mais para Olímpico. Além de ter uma grande vantagem que nordestino não podia desprezar. É que Glória lhe dissera, quando the fora apresentada por Macabéa: "sou carioca da gema!" Olímpico não entendeu o que significava "da gema" pois esta era uma gíria ainda do tempo de juventude do pai de Glória. O fato de ser carioca tornava-a pertencente ao ambicionado clã do sul do país. [...] (Lispector, 2020: p. 53) 
Logo, enquanto convive com Olímpico, Macabéa não é apenas oprimida por ser mulher, mas também é rejeitada por sua condição social e região geográfica de nascença. Retornando à Leite, percebe-se que a personagem até tenta reinscrever o desejo em sua vida. Como ser humano e, pois, ser desejante, ela encontra em Olímpico o seu objeto de prazer. Mas, como não há uma relação de alteridade fundamental entre os dois em decorrência do machismo, do sulismo e do classismo de Olímpico, Maca passa novamente a ser atravessada pela falta (Leite, 20II: p. 4I), como é o costumeiro em sua vida. Algo lhe falta (Leite, 20II: p. 4I), mas esse algo não é a aspirina (ingerida após o término do namoro) e, sim, um novo objeto de prazer (Leite, 2011: p. 4I). A opressão machista e a rejeição classista e sulista, pois, são os outros dois significantes que amarram a sua angústia.

Já a ideia de sentir prazer outra vez ganha os seus pensamentos ao final da narrativa quando ela - por sugestão de, e empréstimo concedido por, Glória (Lispector, 2020: p. 63, 64) - resolve consultar Madama Carlota, uma cartomante a cujos serviços a própria colega de trabalho recorrera. Como o próprio narrador diz após Macabéa sair do apartamento onde fizera a consulta, "a cartomante lhe decretara sentença de vida" (Lispector, 2020: p. 72). Haja vista que, conforme diz Leite, "Ser desejante é o mesmo que dizer movido pela falta, pois, efetivamente, só há movimento e vida quando o sujeito é atravessado pela falta, isto é, quando algo lhe falta" (2011: p. 4I), Macabéa estava vivendo de forma plena. A cartomante acreditara ter previsto para a moça um futuro casada com um belo estrangeiro rico, chamado Hans (Lispector, 2020: p. 70), o qual Maca já imaginava portando o estereótipo de beleza eurocêntrico enquanto ouvia a cartomante tentando adivinhar o seu futuro, como se lê em:

[...] era sorte demais pegar homem de olhos azuis ou verdes ou castanhos ou pretos, não havia como errar, era vasto o campo das possibilidades." (Lispector, 2020: p. 71)

Porém, o enredo sugere que Carlota confundiu o futuro de Macabéa com o da moça que saiu chorando antes de a protagonista ser atendida. Segundo a própria médium, ela teve a franqueza de dizer para a outra moça "que ela ia ser atropelada" (Lispector, 2020: p. 70), quando, factualmente, quem faleceu em decorrência desse tipo de fatalidade foi a protagonista da história.

Para a literatura psicanalítica, é importante lembrar, contudo, que a morte não é de todo negativa para o ser humano, pois, como o próprio Freud disse, o ser humano usa os seus instintos de morte e, inconscientemente, move-se em direção a ela na tentativa de diminuir ou abolir a tensão de seus estímulos químicos internos (2010: p. 165). Não por acaso, após descrever a morte de sua personagem, S. M. eleva a condição de Macabéa, após o falecimento, à condição de uma pessoa livre quando escreve que "Ela estava enfim livre de si e de nós" (Lispector, 2020: p. 78). Assim, ele denuncia que as próprias tensões internas da personagem, as tensões angustiantes que sempre a moveram com base no desejo de ser amada, seja por sua tia na infância, seja por Olímpico ou por um Hans que nunca a amara, eram, por si, limitadoras do exercício de sua liberdade pela falta cumulativamente potencializada pelos insucessos de suas tentativas. Como nunca se encontrara com Hans e não tivera tempo de se frustrar (afinal, foi atropelada primeiro), não se pode dizer que houve um quarto significante a amarrar a sua angústia, como decorrência das esperanças afetivosexuais que depositara no estrangeiro assim que ouvira Carlota. De todo modo, o fato é que, não acreditando que uma moça cercada por um contexto social tão desfavorável poderia ter um final feliz em vida, S. M. escreveu a sua morte, isto é, colocando-a em uma condição em 
que seu gênero, sua região geográfica de nascença, sua classe social, seus atributos físicos e as suas próprias tensões diante das discriminações vividas não a assolam mais.

\section{CONCLUSÃO}

Recapitulando, dois significantes amarram a angústia de Rodrigo S. M., enquanto têm-se três no caso de Macabéa. De forma detalhada, o narrador-escritor é assolado: pela meta - a qual os seus instintos libidinais se lançam, envolvidos pela tendência de afastaremse do que é sexual - de terminar de escrever a história de Macabéa; e pelo medo da morte, em virtude do fato de amar Macabéa tão profundamente ao ponto de entrelaçar os seus afetos aos dela (sente-se morto quando ela morre, por exemplo) e, como decorrência de todo amor, morrer em vida. Já, no caso da protagonista, amarram a sua angústia: os traumas que residem em seu inconsciente como decorrência da criação que recebera de sua tia carrasca; a opressão sexista que sofreu enquanto namorou o metalúrgico Olímpico de Jesus Moreira Chaves; e a rejeição de caráter classista e sulista que esse mesmo homem reservou-lhe, com o intento de encontrar uma mulher de perfil compatível com os gostos das elites políticas, das quais ele procurou integrar.

\section{REFERÊNCIAS BIBLIOGRÁFICAS}

BATISTA, Bianca Cardoso. Angústia e autoconsciência: o narrador em A hora da estrela. 2018. roo f. Dissertação (Mestrado em Letras) - Programa de Pós-Graduação em Letras, Universidade de Santa Cruz do Sul, 2018.

BONDÍA, Jorge Larrosa. "Notas sobre a experiência e o saber de experiência". Revista Brasileira de Educação, Rio de Janeiro, n. 19, p. 20-28, jan./fev./mar./abr. 2002.

BUTLER, Judith. Problemas de gênero: feminismo e subversão da identidade. Rio de Janeiro: Civilização Brasileira, 2003. 236 p.

EAGLETON, Terry. Teoria da literatura: uma introdução. 6a ed. São Paulo: Martins Fontes, 2006. $387 \mathrm{p}$.

FUKUMITSU, Karina Okajima. A vida não é do jeito que a gente quer. São Paulo: Digital Publish \& Print, 2016.

Revista USP, São Paulo, n. II9, p. 103-II4, out./nov./dez. 2018.

FREUD, Sigmund. Escritos sobre a guerra e a morte. Covilhã: LusoSofia:Press, 2009. 50 p.

Obras completas, volume I2: Introdução ao narcisismo, Ensaios de metapsicologia e outros textos (I914-1916). São Paulo: Companhia das Letras, 2010. 225 p.

. Obras completas, volume i4: História de uma neurose infantil ("O homem dos lobos"), Além do princípio do prazer e outros textos (I917-1920). São Paulo: Companhia das Letras, 20I0. $31 \mathrm{p}$.

- Obras completas, volume i7: Inibição, sintoma e angústia, $\mathrm{O}$ futuro de uma ilusão e outros textos (1926-1929). São Paulo: Companhia das Letras, 2014. 312 p. 
LACAN, Jacques. O seminário, livro r: os escritos técnicos de Freud (1953-1954). $3^{\underline{a}}$ ed. Rio de Janeiro: Zahar, 1986. 336 p.

- O seminário, livro 2: o eu na teoria de Freud e na técnica da psicanálise (19541955). 2- ed. Rio de Janeiro: Zahar, 1985. $415 \mathrm{p}$.

. O seminário, livro ıo: a angústia. Rio de Janeiro: Zahar, 2005.

LEITE, Sonia. Angústia. Rio de Janeiro: Zahar, 2011. 367 p.

LISPECTOR, Clarice. A hora da estrela. $\mathrm{I}^{\mathrm{a}}$ ed. Rio de Janeiro: Rocco, 2020. 87 p.

MENDES, Eliana Rodrigues Pereira. "Pulsão e Sublimação: a trajetória do conceito, possibilidades e limites”. Reverso, Belo Horizonte, ano 33, n. 62, p. 55-68, set. 201 .

SARTRE, Jean Paul. O ser e o nada - Ensaio de ontologia fenomenológica. $20^{\mathbf{a}}$ ed. Petrópolis: Vozes, 2011. 782 p.

SAUSSURE, Ferdinand de. Curso de linguística geral. 27ª ed. Cultrix: São Paulo, 2006.

SIMANKE, Richard Theisen. "O Trieb de Freud como instinto I: sexualidade e reprodução". Scientiæ Studia, São Paulo, v. I2, n. I, p. 73-95, 2014.

SOUZA, Álisson Matutino de. Tradução comentada do texto: "Que é metafísica?”, de Martin Heidegger. 2019. I85 f. Dissertação (Mestrado em Filosofia) - Programa de PósGraduação em Filosofia, Universidade Federal de Uberlândia, Uberlândia, 2019. 